\title{
Relationships among biological elements (macrophytes, macroinvertebrates and ichthyofauna) for different core river types across Europe at two different spatial scales
}

\author{
Paulo Pinto ${ }^{1, *}$, Manuela Morais ${ }^{1}$, Maria Ilhéu ${ }^{1} \&$ Leonard Sandin ${ }^{2}$ \\ ${ }^{1}$ Centre of Applied Ecology, Water Laboratory, University of Évora, Largo dos Colegiais, 7001 Évora codex, Portugal \\ ${ }^{2}$ Department of Environmental Assessment, Swedish University of Agriculture Sciences, Valvagen 3, PO Box 7050, \\ S-75007 Uppsala, Sweden \\ (*Author for correspondence: Fax: +35-1-184735 71; E-mail: ppinto@uevora.pt)
}

Key words: macrophytes, macroinvertebrates, fishes, mantel correlations, lotic ecosystems, spatial scale, linkages

\begin{abstract}
The objective of this study was to evaluate differences in correlations among Biological Elements and environmental parameters for different river types, analysed at two different spatial scales. A total of 82 sites, with at least good ecological status, were sampled across Europe, representing three core river types: Mountain rivers (26 sites); Lowland rivers (29 sites) and Mediterranean rivers (17 sites). At each site samples of macrophytes, macroinvertebrates and fishes were taken during spring, following the methodological procedures established by the European STAR project. Environmental parameters were also recorded, based on a site protocol developed by the European projects AQEM and STAR. Environmental parameters were divided into three categories: aquatic habitats (mesohabitat scale), global features (reach scale) and obligatory typology parameters of Water Framework Directive (WFD) (geographical scale). Data were analysed to evaluate at the two scales, first, relationships among biological elements, and second, relationships between biological elements and environmental parameters. Within each river type, correlation matrices (Bray-Curtis distance) were calculated separately for each biological element and for each category of environmental parameters. All biological elements were correlated $(p<0.01)$ to the larger spatial scale: macrophytes and macroinvertebrates are more correlated in lowland and mountain rivers, while in Mediterranean rivers, fish and macrophytes presented higher correlations. These links tend to be consistent for different spatial scales, except if they are weak on a larger regional scale, obligatory parameters of WFD were, in most cases, significantly correlated with the three biological communities $(p<0.05)$. Results at different spatial scales supported the hierarchical theory of river formation. Reach and mesohabitat environmental parameters tend to explain aquatic communities at a lower spatial scale, while geographical parameters tend to explain the communities at a major spatial scale.
\end{abstract}

\section{Introduction}

Rivers and streams are composed of a hierarchical system of patches of different ages, sizes and environmental conditions, thus creating a multiplicity of ecological niches (Beisel et al., 1998;
Crook et al., 2001; Li et al., 2001). These niches are occupied by communities of organisms with different biological and ecological characteristics (algae, macrophytes, invertebrates and fishes), permitting the establishment of a complex net of relationships among organisms and communities. 
Biological interactions like predation and competition are generally recognized as biological interactions with a direct influence on aquatic biodiversity (Rosenfeld, 1997; Dahl \& Greenberg, 1998; Warfe \& Barmuta, 2004). However, other indirect relationships may occur, like those related to macrophyte growth. Macrophyte abundances tend to increase habitat diversity, thus creating refuges for invertebrates and young fishes (Dahl \& Greenberg, 1998; Cheruvelil et al., 2000; Allouche, 2002; Wright et al., 2002; Zrum \& Hann, 2002; Balci \& Kennedy, 2003), providing surface areas for periphyton development and also influencing current velocity (Armitage, 1995; Armitage \& Gunn, 1996).

Aquatic communities also depend on different environmental scales: mesohabitat scale; reach scale; catchment scale and regional scale (see Jensen et al., 1996; Beisel et al., 1998; Verdonschot, 2000; Crook et al., 2001; Verdonschot \& Nijboer, 2004). The influence of these different scales on aquatic communities is dependent on organism's characteristics, namely ecological sensitivity, life cycles, mobility and size (Tolonen et al., 2003). Fishes that can move along the river are expected to be more dependent on catchment scale than other communities with lower mobility, and for this reason they are more dependent on reach or mesohabitat parameters.

The intensity and frequency of disturbance (Townsend, 1989; Voelz \& McArthur, 2000; Ward \& Tockner, 2001; Vieira et al., 2004) are clearly related to catchment and regional scales (Beisel et al., 1998; Crook et al., 2001; Li et al., 2001; Reyjol et al., 2003), and may be determinant factors for the strength of interaction among organisms and communities. Flood events may induce modifications on riverbed shape (Armitage \& Cannan, 2000; Petts, 2000; Bio et al., 2002) and influence the shift in species composition, particularly in streams presenting high inter-annual flow variability (Bernardo et al., 2003). These interactions are also influenced by the longitudinal dimension of lotic ecosystems (Vannote et al., 1980; Ward, 1989), being expected higher dependency from the surrounding terrestrial ecosystem to upstream reaches (Mountain rivers) than to downstream reaches (Lowland rivers).
Many studies have theorized about the implications of all these relationships on aquatic ecosystem functioning, with the main focus at a very local scale (Casas, 1997; Cheruvelil et al., 2000; Zrum \& Hann, 2002; Wagner \& Bretschko, 2003; Zimmer et al., 2003; Warfe \& Barmuta, 2004; Willis et al., 2005). However, few studies have addressed the hierarchy of these relationships and their patterns at a wider regional scale.

In this study, three different core river types (mountain, lowland and Mediterranean rivers) with low-human impacts were investigated at a European regional level, during spring. The objective is to answer to the following questions: (1) are links among biological elements different for different core river types?; (2) if yes, are they consistent at different spatial scales?; (3) are biological elements of each core river type explained for specific environmental parameters?; (4) if yes, are they specific to precise spatial scales?

\section{Study area}

Within the framework of the European project STAR (EVK1-CT-2001-00089), 82 sites were sampled across Europe during spring 2003, covering nine different countries. Sites were grouped into three core river types, according to the results of previous studies across Europe (Verdonschot \& Nijboer, 2004; Verdonschot, 2006) based on the hierarchical approach to stream formation (Jensen et al., 1996; Verdonschot, 2000): (1) mountain rivers (26 sites) including an Austrian river (A05), two Czeck rivers $(\mathrm{C} 04, \mathrm{C} 05)$ and two German rivers (D04, D06); (2) lowland rivers (29 sites) including a German river (D03), a Danish river (K02), a British river (U23) and two Swedish rivers (S05, S06); (3) Mediterranean rivers (17 sites), including a Portuguese river (P04), an Italian river (I06) and two Greek rivers (H04, H06). These groups were established in order to understand differences in river functioning at a large geographical scale. Since river groups include sites with contrasting geographical locations, a set of subgroups with relatively homogenous features were used in data analysis. These groups and subgroups correspond to regional and local scales of the hierarchical approach (Jensen et al., 1996; Verdonschot, 2000). 


\section{Methodology}

\section{Environmental parameters}

Each site was described by a protocol developed within the European projects AQEM and STAR. This site protocol covers a set of environmental parameters related to different spatial scales (AQEM consortium, 2002). Some of these parameters were selected and grouped into three categories, based on different spatial scales (Table 1): aquatic habitats (mesohabitat scale); global features of the site (reach scale) and obligatory variables of Water Framework Directive (WFD) System B (larger regional scale). Aquatic habitats and global features were evaluated in the field, while the WFD parameters were evaluated using Geographical Information Systems.

\section{Biotic parameters}

Fish, macroinvertebrates and macrophytes were sampled at all sites during the spring of 2003. Macrophytes were recorded and percentage cover of each species was estimated along a reach of $100 \mathrm{~m}$. The final results were expressed by nine abundance classes: $1 \leq 0.1 \%$ cover; $2=0.1-1 \%$; $3=1-2.5 \% ; 4=2.5-5 \% ; 5=5-10 \% ; 6=10-25 \%$; $7=25-50 \% ; 8=50-75 \%$ and $9 \geq 75 \%$ cover.

A multihabitat procedure developed by AQEM consortium (2002) was adopted to sample benthic macroinvertebrates. A total of 20 Surber samples $(25 \mathrm{~cm}$ square side with a mesh size of $0.5 \mathrm{~mm}$ )

Table 1. Evaluated environmental parameters included in each category. In bold are mentioned the abbreviations of some environmental parameters used in the subsequent tables

\begin{tabular}{|c|c|c|}
\hline $\begin{array}{l}\text { Aquatic habitats } \\
\text { ( } \% \text { of coverage })\end{array}$ & Global features & $\begin{array}{l}\text { Water framework } \\
\text { directive system B }\end{array}$ \\
\hline (Mesohabitat scale) & (Reach scale) & (Geographical scale) \\
\hline Mineral substrates & Mean depth water body (m) & Longitude \\
\hline Hygropetric sites & $\begin{array}{l}\text { Maximum depth water body }(\mathrm{m}) \\
\text { max. depth }\end{array}$ & Latitude \\
\hline Megalithal $>40 \mathrm{~cm}$ & $\begin{array}{l}\text { Mean slope of the valley floor }(\%) \\
\text { mean slope val. }\end{array}$ & Altitude (m) \\
\hline Macrolithal $>20-40 \mathrm{~cm}$ & $\begin{array}{l}\text { Shading at zenith (foliage cover) } \\
\text { shading }\end{array}$ & $\begin{array}{l}\text { Catchments area } \\
\left(\mathrm{km}^{2}\right) \text { catch. Area }\end{array}$ \\
\hline Mesolithal $>6-20 \mathrm{~cm}$ & $\begin{array}{l}\text { Average width of woody riparian } \\
\text { vegetation }(\mathrm{m}) \text { left width rip. }\end{array}$ & \\
\hline Microlithal $>2-6 \mathrm{~cm}$ & $\begin{array}{l}\text { Average width of woody riparian } \\
\text { vegetation }(\mathrm{m}) \text { right width rip. }\end{array}$ & \\
\hline Akal $>0.2-2 \mathrm{~cm}$ & $\begin{array}{l}\text { Shoreline covered with woody riparian } \\
\text { vegetation left length rip. }\end{array}$ & \\
\hline Psammal/Psammopelal & $\begin{array}{l}\text { Shoreline covered with woody riparian } \\
\text { vegetation right length rip. }\end{array}$ & \\
\hline \multicolumn{3}{|l|}{ Argyllal $<6 \mu \mathrm{m}$} \\
\hline \multicolumn{3}{|l|}{ Biotic microhabitats } \\
\hline \multicolumn{3}{|l|}{ Macro-algae } \\
\hline \multicolumn{3}{|l|}{ Micro-algae } \\
\hline \multicolumn{3}{|l|}{ Submerged macrophytes } \\
\hline \multicolumn{3}{|l|}{ Emergent macrophytes } \\
\hline \multicolumn{3}{|c|}{ Living parts of terrestrial plants } \\
\hline \multicolumn{3}{|c|}{ Ter. plants } \\
\hline \multicolumn{3}{|l|}{ Xylal } \\
\hline \multicolumn{3}{|l|}{$\mathrm{CPOM}$} \\
\hline FPOM & & \\
\hline
\end{tabular}


were taken, in a reach of $100 \mathrm{~m}$, covering the different habitats. The proportion of Surber samples from each habitat was determined on the basis of the proportion of total reach area occupied by each habitat. Habitats represented by less than 5\% of the total area were excluded. The samples were fixed in situ with $96 \%$ alcohol or with a $40 \%$ formalin solution. In the laboratory, samples were sieved ( $0.5 \mathrm{~mm}$ mesh size) and the organisms sorted by naked eye. Sorted organisms were identified to the lowest taxonomic level possible.

Fish sampling took place in wadeable reaches with high-habitat diversity. Reach length was 10 times stream width (minimum $100 \mathrm{~m}$ ), with special exceptions (minimum $50 \mathrm{~m}$ ). Stop nets to enclose the fishing area and multiple fishing runs (minimum 2) were recommended. Fishing was conducted in a discontinuous way, always in a downstream-upstream direction. Equipment disinfection between watercourses was recommended to prevent disease spread. All captured fish were identified to the species level and measured in the field. All specimens were returned to water (with exceptions to confirm identification). Mesh-cages and an oxygen diffuser were used whenever necessary. For additional information on sampling methods of all biological elements see Furse et al. (2006).

\section{Data analysis}

A taxonomic adjustment was made to avoid the inclusion of different taxonomic levels. For this reason, Mediterranean macroinvertebrates data were treated at the family level, because one of the countries only attained this level of identification.

Taxa with a frequency occurrence lower than $10 \%$ and present in samples with less than two individuals were excluded. To prevent distortions caused by the most abundant taxa, species abundances were $\log (x+1)$ transformed. Environmental data were standardized to centre and reduce variation:

$$
\mathrm{ST}=\frac{x-\text { mean }}{\text { medium deviation }}
$$

where $x$ is raw data and ST is standardized data.

Indirect gradient analysis was carried out to detect, inside each core river type, ecological gradients and subgroups of sites ecologically consistent to a lower regional scale. Sites from countries that, in the ordinations of the biological elements, are consistently close together were assumed as subgroups of the respective core river type. Principal Component Analysis (PCA) or Correspondence Analysis (CA) were carried out if the gradient lengths of a preliminary Detrended Correspondence Analysis (DCA) were, respectively, lower or higher than three (ter Braak \& Smilauer, 1998).

For each core river type, similarity matrices (site $\times$ site) were calculated, using Bray-Curtis distance, to the three biological elements (taxa abundances for macroinvertebrate and fishes, and percentage of cover for macrophytes) and to the three categories of environmental parameters. Mantel correlations were first calculated among the three biological elements, and with these results a new similarity matrix was calculated to build a cluster showing the hierarchical linking among the biological elements. Second, new mantel correlations were calculated between each environmental data category and each biological element. The objective of this second step was to evaluate global dependencies between biological elements and environmental parameters. To go into further detail, it was necessary to evaluate the environmental parameters that account more for the global mantel correlations carried out in the second step. This evaluation was obtained by performing, within each environmental data category, a set of mantel correlations between the single parameters similarity matrices and the biological similarity matrices. The single parameters that got higher correlation coefficients were considered to be the most important to explain the global mantel correlations. This more detailed evaluation was done to mantel correlations whose percentage of significance was lower than 0.1. Mantel correlations among matrices were calculated by Pearson correlations and the respective percentage of significance evaluated by a MonteCarlo permutation test (999 permutations). This same procedure was carried out on the subgroups of sites established within each core river type, to evaluate if the observed patterns are similar within a lower spatial scale. Subgroups composed by only one country were excluded from this new analysis, because the number of observations was too small 
to get robust statistical tests. A flow diagram summarizing all these steps can be seen in Fig. 1. Mantel correlations and clusters were done by the software PRIMER 5 for windows, Version 5.2.2 (Clark \& Warwick, 1980).

\section{Results}

Differences in mean abundance and mean richness of the three aquatic communities in each core river type were evident (Table 2). Macrophyte and fish richness were higher in lowland rivers, while the highest macroinvertebrate richness was observed in Mountain Rivers, although presenting a high variability. Fish communities were at their lowest abundances in Mountain

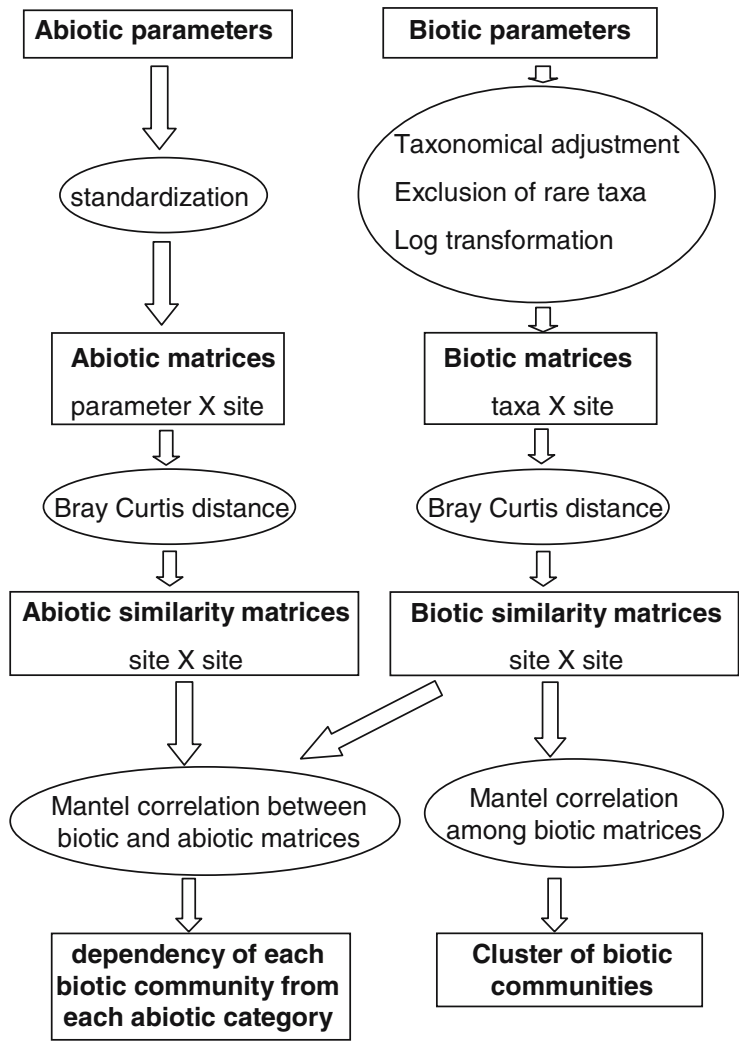

Figure 1. Flow diagram of abiotic and biotic parameters data treatment (similarity matrices and mantel correlations) followed for each core river type and to its respective subgroups. Inside the rectangle are the partial and the final results obtained during the treatment. Inside the elliptical shapes are mentioned the actions carried out.
Table 2. Mean abundance and richness of the three aquatic communities in each core river type. Standard deviation in parentheses. Mean abundances of macrophytes were not calculated because data are expressed in abundance classes

\begin{tabular}{lcr}
\hline & Mean abundance & Mean richness \\
\hline Lowland rivers & & \\
Macrophytes & - & $7.1(4.6)$ \\
Invertebrates & $2817(2864)$ & $38.7(8.9)$ \\
Fishes & $10,771(24,531)$ & $6.1(2.5)$ \\
Mountain rivers & & \\
Macrophytes & - & $3.1(1.4)$ \\
Invertebrates & $3739(2824)$ & $49.1(8.9)$ \\
Fishes & $3792(2362)$ & $2.2(1.1)$ \\
Mediterranean rivers & \\
Macrophytes & - & $20.4(2.1)$ \\
Invertebrates & $2060(2822)$ & $3.8(2.2)$ \\
Fishes & $10,727(12,545)$ &
\end{tabular}

Rivers. Macrophytes and fishes presented low richness for Mediterranean river although slightly higher than Mountain Rivers.

The ordinations plotted in Figures 2-4 showed that, although the different spatial patterns observed, within each core river type, for each biological element, it is possible to extract consistent groups of countries representing lower spatial scales. For Mountain Rivers (Fig. 2), German (D05, D06) and Czeck rivers (C04, C05) tend to form two distinct groups in both invertebrate and fish ordinations, as opposed to the macrophyte ordination where no consistent group is detectable. The Austrian river (A05) is grouped with German rivers concerning fish ordination, while the invertebrate ordination, despite the proximity to the German group, tends to be separate. A similar tendency of the Austrian river to be an independent group was observed in the macrophyte ordination. In this ordination, Austrian sites tend to be located on the extreme negative of the first axis. Thus, two subgroups of rivers, mainly defined by invertebrate and fish communities, can be established within Mountain Rivers, D04/D06 and C04/C05, respectively.

Concerning Lowland rivers (Fig. 3), as detected for Mountain Rivers, it was only possible to establish different groups in relation to 

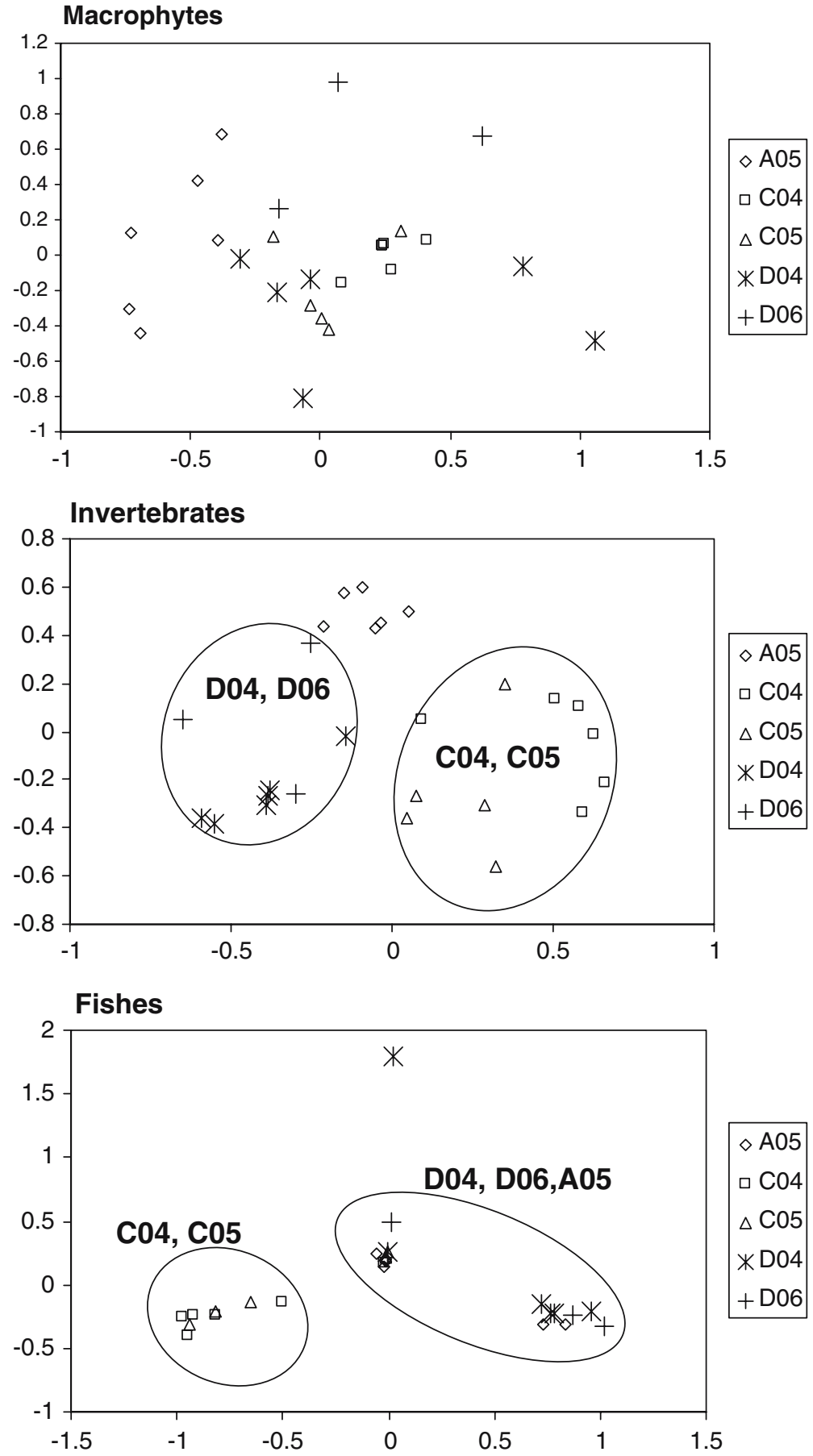

Figure 2. Ordination of biological elements to Mountain Rivers. The rounded shapes indicate the subgroups pointed out by the plotted ordinations.

invertebrate and fish ordinations. However, the established groups are no longer the same. Swedish rivers (S05, S06) as well as Danish and British rivers (K02, U23) tend to form two different groups. However, a lack of consistency was observed in relation to the German river (D03). It 

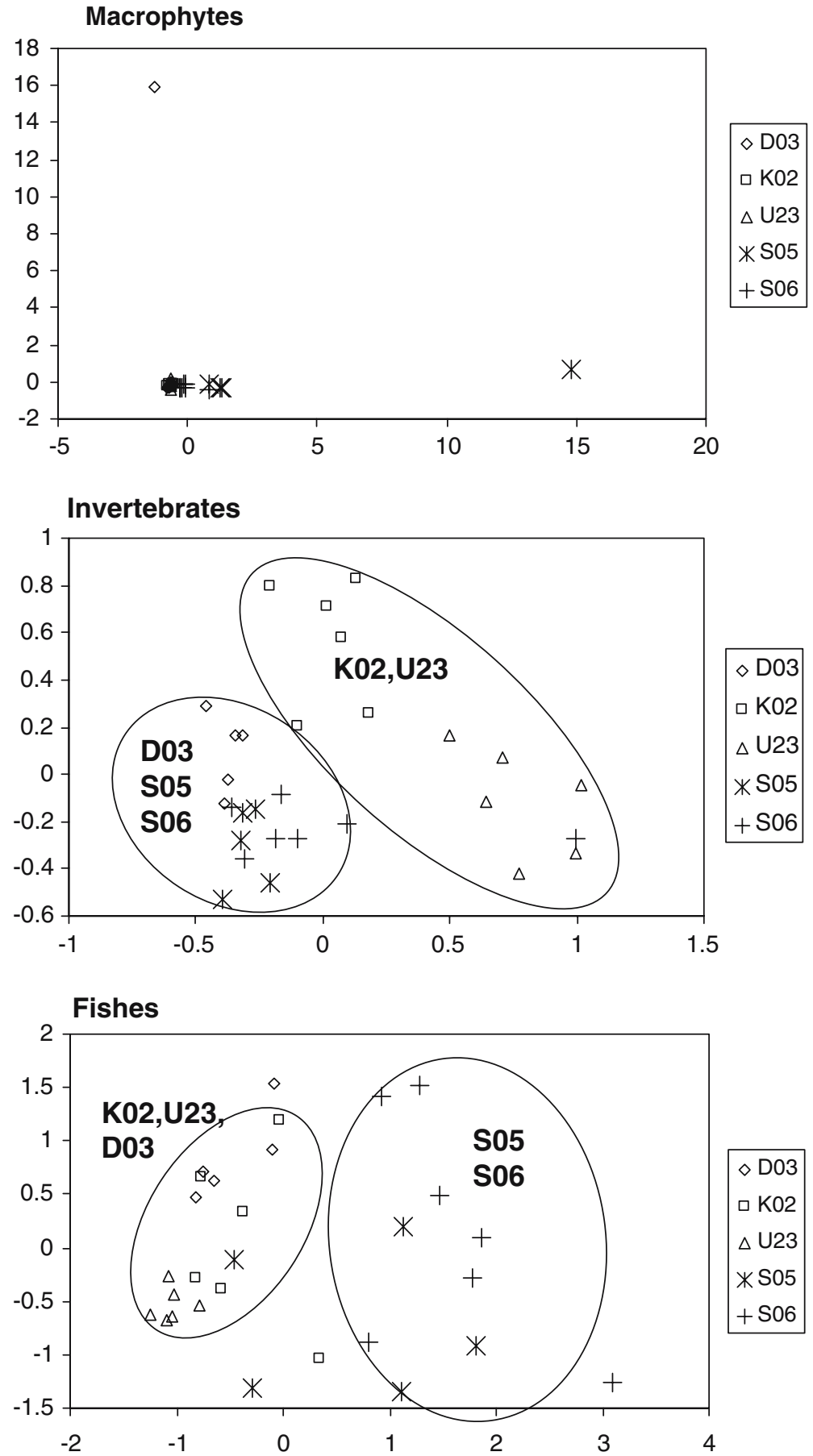

Figure 3. Ordination of biological elements to Lowland rivers. The rounded shapes indicate the subgroups pointed out by the plotted ordinations.

is grouped with Swedish rivers for the invertebrate ordination, being included in the other group for the fish ordination. As a result of this lack of consistency, this German river was excluded and two subgroups were established for Lowland rivers S05/S06 and K02/U23, respectively. 

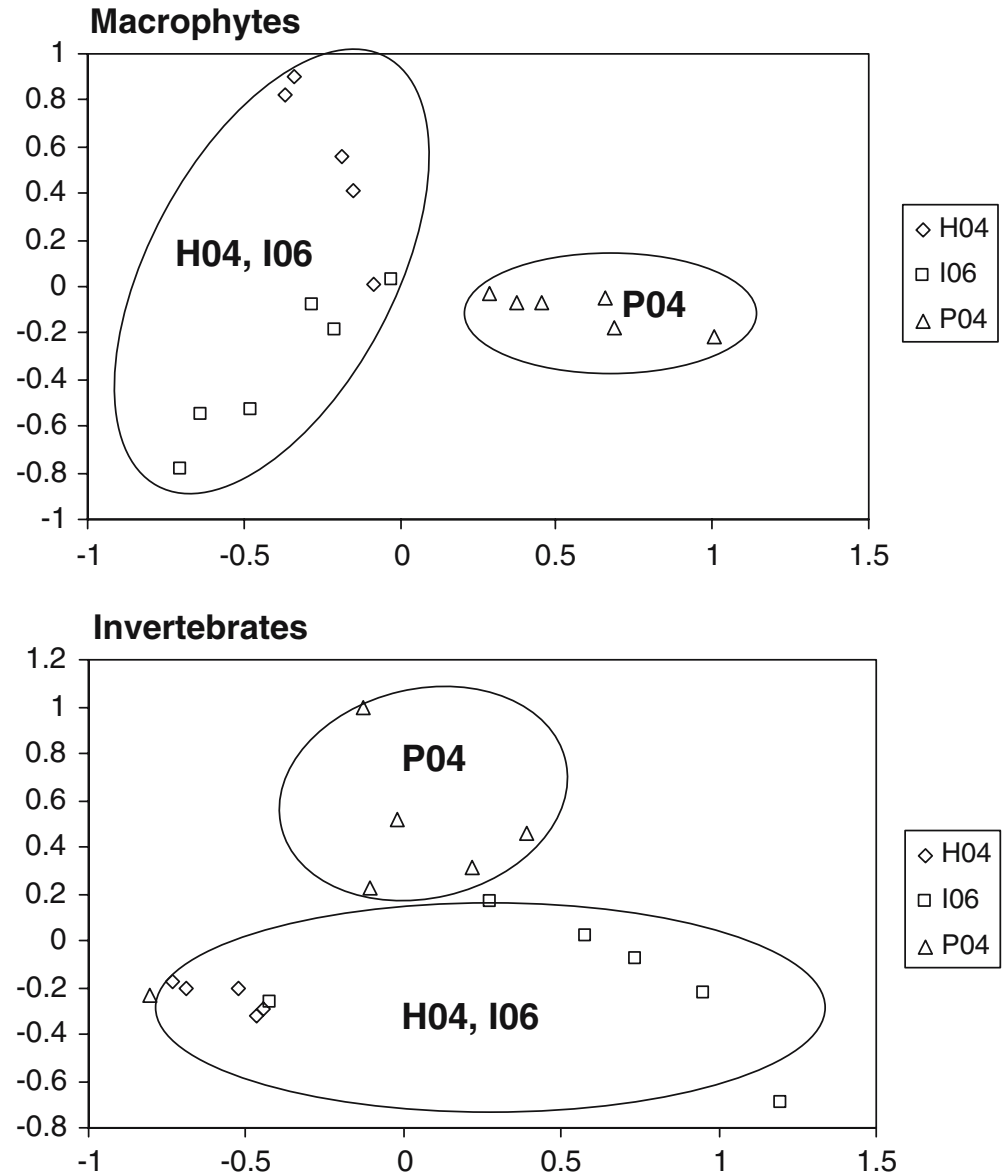

\section{Fishes}

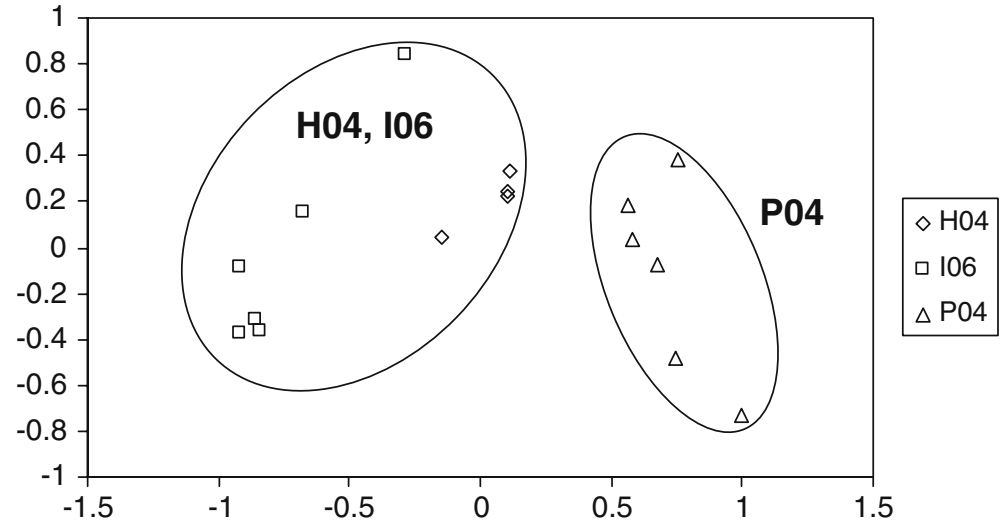

Figure 4. Ordination of biological elements to Mediterranean rivers. The rounded shapes indicate the subgroups pointed out by the plotted ordinations.

The ordinations plotted for Mediterranean rivers (Fig. 4) permitted the detection of the two same groups for the three biological elements. Portuguese rivers tend to be consistently separated from Greek and Italian rivers and, for this reason, only one subgroup was established for Mediterranean rivers H04/I06. 
Cluster analysis and Mantel tests, carried out to a larger spatial scale, showed significant correlations among the three aquatic communities $(p<0.01)$ for the three core river types (Fig. 5). Lowland and Mountain rivers displayed similar patterns. For those core river types, the clusters first agglomerated macrophytes and invertebrates.
In contrast, the first agglomeration for Mediterranean rivers was between macrophytes and fishes (Fig. 5).

The mantel correlations obtained between environmental parameter matrices and aquatic community matrices, as well as the environmental parameters that account more for the mantel

Table 3. Percentage of significance obtained by mantel correlations between environmental categories and each biological element, for the three core river types $(* p<0.05 ; * *<0.01)$. Down mantel correlations whose $p<0.1$ are mentioned the most important single parameters that account for the global correlation

\begin{tabular}{|c|c|c|c|}
\hline & \multicolumn{3}{|l|}{ Aquatic communities } \\
\hline & Macrophytes & Invertebrates & Fishes \\
\hline \multicolumn{4}{|l|}{ Mountain } \\
\hline Habitat & $22.8 \%$ & $5.6 \%$ & $16.6 \%$ \\
\hline \multirow[t]{4}{*}{ Global features } & $4.8 \%(*)$ & $5 \%$ & $8.1 \%$ \\
\hline & Stream width (0.319) & Length rip. vegt. (0.295) & Length rip. vegt. (0.207) \\
\hline & Length rip. vegt. (0.284) & Stream width $(0.182)$ & Shading (0.139) \\
\hline & Width rip. veget.(0.165) & Shading $(0.128)$ & \\
\hline \multirow[t]{4}{*}{ WFD } & $6.3 \%$ & $0.1 \%(* *)$ & $0.3 \%(* *)$ \\
\hline & Longitude (0.444) & Latitude (0.550) & Latitude $(0.415)$ \\
\hline & Latitude (0.214) & Altitude (0.339) & Catch. area (0.377) \\
\hline & & & Altitude $(0.377)$ \\
\hline \multicolumn{4}{|l|}{ Lowland } \\
\hline \multirow[t]{6}{*}{ Habitat } & $0.1 \%(* *)$ & $2.9 \%(*)$ & $0.1 \%(* *)$ \\
\hline & Psammal (0.268) & Psammal (0.344) & FPOM (0.149) \\
\hline & Microlithal (0.256) & Microlithal (0.318) & Xylal (0.141) \\
\hline & Subm. macroph. (0.249) & CPOM (0.169) & Microlithal (0.118) \\
\hline & FPOM $(0.202)$ & Akal (0.162) & Megalithal (0.117) \\
\hline & & FPOM (0.152) & \\
\hline \multirow[t]{4}{*}{ Global features } & $0.6 \%(* *)$ & $21.3 \%$ & $27.3 \%$ \\
\hline & Shading $(0.241)$ & & \\
\hline & Max. depth $(0.225)$ & & \\
\hline & Length rip. vegt. (0.156) & & \\
\hline \multirow[t]{3}{*}{ WFD } & $4.0 \%(*)$ & $0.1 \%(* *)$ & $0.1 \%(* *)$ \\
\hline & Longitude (0.128) & Altitude (0.302) & Longitude (0.124) \\
\hline & & Longitude (0.295) & \\
\hline \multicolumn{4}{|l|}{ Mediterranean } \\
\hline \multirow[t]{5}{*}{ Habitat } & $32.7 \%$ & $38.5 \%$ & $0.5 \%(* *)$ \\
\hline & & & Mesolithal (0.310) \\
\hline & & & CPOM (0.288) \\
\hline & & & Megalithal (0.248) \\
\hline & & & Akal (0.222) \\
\hline Global features & - & - & - \\
\hline \multirow[t]{4}{*}{ WFD } & $0.1 \%(* *)$ & $1.8 \%(*)$ & $0.2(* *)$ \\
\hline & Longitude (0.588) & Catch. area $(0.230)$ & Longitude (0.694) \\
\hline & Catch. area (0.528) & Latitude $(0.216)$ & Catch. area (0.614) \\
\hline & Latitude $(0.456)$ & Longitude (0.216) & Latitude $(0.511)$ \\
\hline
\end{tabular}


correlations are shown in Table 3. Habitat data category was only significantly correlated with all biological elements on Lowland rivers, FPOM being an important parameter in all correlations. Concerning the inorganic habitats, fine sediments (psammal) tend to be more important to macrophytes and invertebrates than to fishes, where sediment with larger granulometry (megalithal) tends to increase its importance. The same importance of larger inorganic sediments to fish communities was also observed to Mediterranean rivers (mesolithal and megalithal).

Macrophytes were the only biological element to show significant correlations $(p<0.05)$ with the habitat data category, the importance of the shoreline covered with woody riparian vegetation (length rip. veget.) being noticeable for both Mountain and Lowland rivers.

Finally, and also at the same larger spatial scale, for almost all cases, biological elements were significantly correlated with WFD data category. Latitude and longitude were consistently important in the great majority of the situations, denoting the biogeographical distribution of the taxa across Europe. In the specific case of Mediterranean rivers, catchment area, at this spatial scale, seems to be a key factor in explaining the establishment of aquatic communities.

Going into further detail to a lower spatial scale (subgroups within each core river type), the same data treatment was carried out in relation to the subgroups, and their patterns compared with the respective core river type.

Cluster analysis for subgroups of each core river type (Figs. 5-7) showed similar results for Lowland and Mediterranean rivers (Figs. 6 and 7). The Mountain rivers clusters were different for each subgroup (Fig. 5), and in contrast with the two other core river types, no significant correlations $(p>0.05)$ were detected among the three aquatic communities (Fig. 6).

Biological elements of Mountain Rivers (two subgroups, Table 4) showed the least number of significant correlations with the environmental parameter categories (three significant correlations at $p<0.05$ for the 18 correlations carried out). In contrast, Lowland rivers (two subgroups, Table 5) presented the highest number of significant correlations (13 significant correlations at $p<0.05$ for

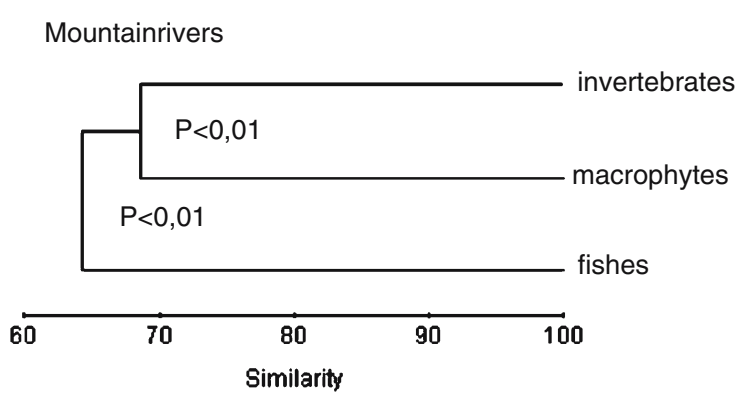

Lowlandrivers
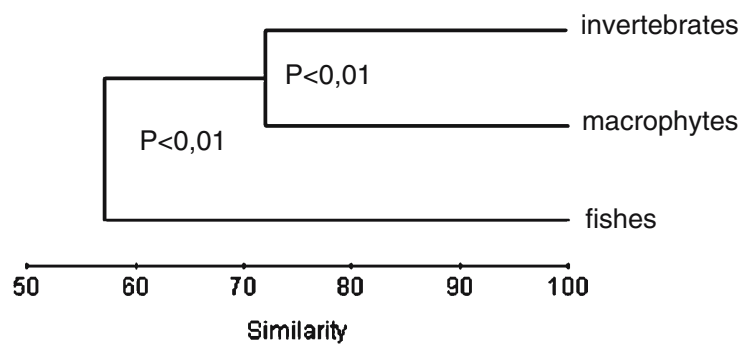

Mediterraneanrivers
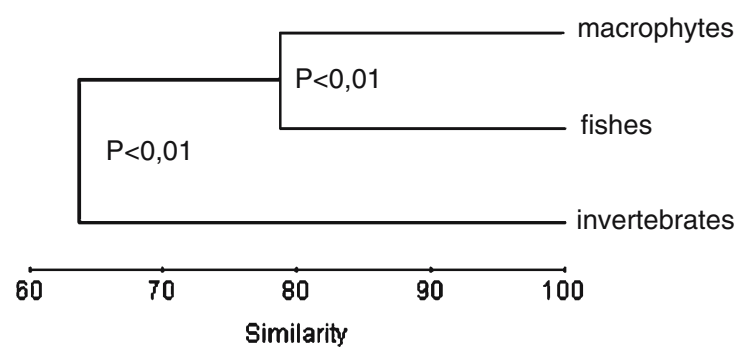

Figure 5. Cluster analyses of all biological elements for Mountain, Lowland and Mediterranean rivers. Critical level of significance $(p)$ mentioned for all the partial agglomerations.

the 18 correlations carried out). Aquatic communities of the Mediterranean subgroup were also significantly correlated $(p<0.05)$ to both habitat data category and WFD data category parameters (Table 6), with the exception of macrophytes (five significant correlations at $p<0.05$ for the six correlations carried out).

Macrophyte and fish communities from subgroups of Mountain rivers (biological elements with the lowest observed richness, see Table 2), contrasting with the other core river types, are the only biological element that did not present any significant correlation with the environmental parameters. Concerning invertebrates, the influence of latitude and longitude on the global 
Rivers C04, C05

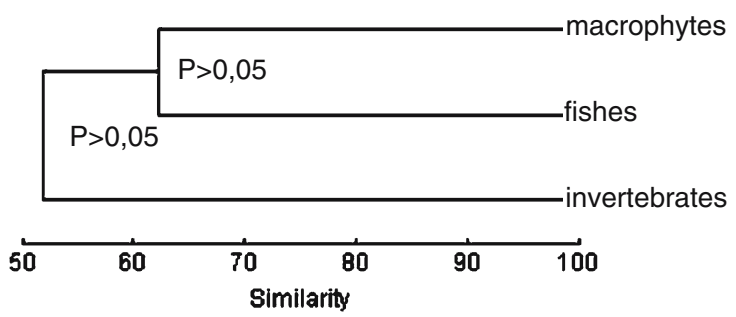

Rivers D04, D06

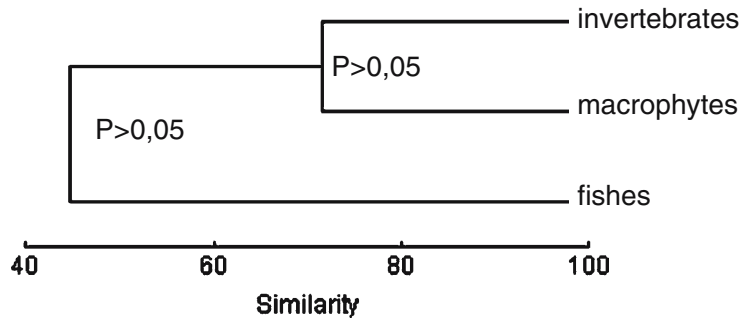

Figure 6. Cluster analyses of all biological elements for subgroups of Mountain Rivers. Critical level of significance $(p)$ mentioned for all the partial aglomerations.

Rivers S05, S06

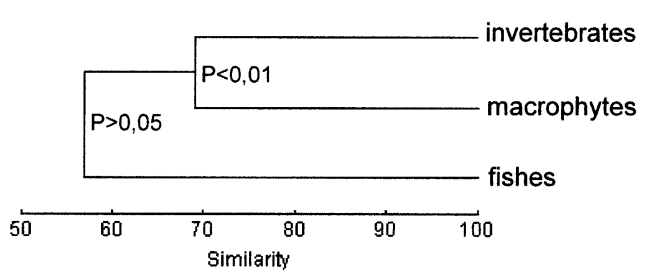

Rivers K02, U23

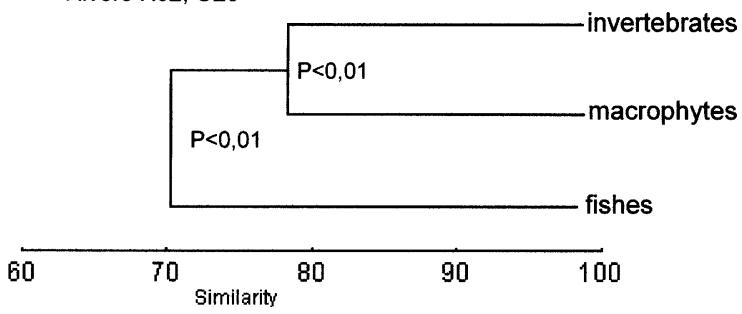

Figure 7. Cluster analyses of all biological elements for subgroups of Lowland, rivers. Critical level of significance $(p)$ mentioned for all the partial aglomerations.

correlations is remarkable, denoting that biogeographical aspects of taxa distributions are still important at this lower spatial scale.

Two quite different patterns were observed for the subgroups of Lowland rivers. Swedish rivers (S05, S06), in contrast to Danish and British rivers
(K02, U23), presented a low number of significant correlations between biological elements and environmental parameters categories. Analysing the WFD data category parameters in more detail, it was observed that longitude is very important to the K02/U23 subgroup, a fact that could be expected as a result of the accentuated geographical isolation from Denmark and the UK. In any case, habitat and global features data categories are all significantly correlated with all biological elements $(p<0.01)$, pointing out that, despite the geographical isolation, rivers of this subgroup are clearly consistent and the aquatic communities are clearly predicted by the environmental parameters. Also, for these rivers, fine inorganic sediments are important to all biological elements, an expected feature due to the importance of the deposition processes in Lowland rivers. Concerning Swedish rivers, catchment area is an important WFD parameter, denoting variability in discharge and hydrodynamics inside this subgroup, a fact that agrees with the importance of inorganic habitats of very different granulometries for invertebrate communities. The mean slope of the valley (important to fish communities) is also a parameter that can be related to the catchment area.

In relation to Mediterranean rivers, as occurred in the larger spatial scale, catchment area continues to be an in important factor in this lower spatial scale, emphasizing the dependence of all biological elements on the water availability throughout the year. At this lower scale, the fine inorganic sediments are important to invertebrate and fish communities, but larger inorganic sediments also account for the correlation with fishes (megalithal). Due to the geographical isolation from Italy and Greece, longitude is an important factor, still at this scale (Fig. 8).

\section{Discussion}

Mountain Rivers, due to their higher hydrodynamics, are less suitable for macrophyte development, which also may affect fish communities. Vegetated habitats are important refuge areas against high currents and aquatic predators, particularly for small fish (e.g., Allouche, 2002; Shoup et al., 2003). For invertebrates, the pattern of greater richness may result from higher hydrodynamic disturbance in mountain rivers, 
Table 4. Percentage of significance obtained by mantel correlations between environmental categories and each biological element, for Mountain Rivers $(* p<0.05 ; * *<0.01)$. Down mantel correlations whose $p<0.1$ are mentioned the most important single parameters that account for the global correlation

\begin{tabular}{|c|c|c|c|}
\hline & \multicolumn{3}{|c|}{ Aquatic communities } \\
\hline & Macrophytes & Invertebrates & Fishes \\
\hline \multicolumn{4}{|l|}{ Rivers C04, C05 } \\
\hline Habitat & $69.8 \%$ & $19.6 \%$ & $45.8 \%$ \\
\hline Global features & $56.4 \%$ & $71.0 \%$ & $93.9 \%$ \\
\hline \multirow[t]{3}{*}{ WFD } & $23.0 \%$ & $2.0 \%(*)$ & $78.2 \%$ \\
\hline & & Longitude (0.630) & \\
\hline & & Latitude $(0.530)$ & \\
\hline \multicolumn{4}{|l|}{ Rivers D04, D06 } \\
\hline \multirow[t]{5}{*}{ Habitat } & $54.0 \%$ & $0.1 \%(* *)$ & $12.3 \%$ \\
\hline & & Ter. plants $(0.610)$ & \\
\hline & & Xylal $(0.436)$ & \\
\hline & & Microlithal (0.369) & \\
\hline & & CPOM (0.364) & \\
\hline \multirow[t]{5}{*}{ Global features } & $25.0 \%$ & $9.2 \%$ & $24.6 \%$ \\
\hline & & Stream width $(0.540)$ & \\
\hline & & Mean solpe val. $(0.320)$ & \\
\hline & & Max. depth $(0.285)$ & \\
\hline & & Width rip. veget. (0.258) & \\
\hline \multirow[t]{4}{*}{ WFD } & $29.0 \%$ & $0.1 \%(* *)$ & $19.4 \%$ \\
\hline & & Catch. area $(0.634)$ & \\
\hline & & Longitude (0.527) & \\
\hline & & Altitude $(0.512)$ & \\
\hline
\end{tabular}

thus maintaining invertebrate communities under a constant level of intermediate disturbance, diminishing competition and increasing diversity (Townsend, 1989; Voelz \& McArthur, 2000; Wright \& Li, 2002; Willis et al., 2005). Despite those strong differences observed between the richness of aquatic communities between Mountain and Lowland rivers, similar clusters were obtained with respect to the correlations among the three communities. Higher correlations were observed between macrophytes and invertebrates, suggesting the importance of macrophytes as refuges for invertebrates (Rosenfeld, 1997; Voelz \& McArthur, 2000; Zrum \& Hann, 2002; Balci \& Kennedy, 2003; Strayer et al., 2003; Warfe \& Barmuta, 2004) from predation and hydrodynamic peaks. Fishes that can easily move along rivers are less dependent on local variables than invertebrates and macrophytes. Despite the high-correlation observed between macrophytes and fishes in Mediterranean rivers, no direct relationship occurs between these two communities. This relationship may result from water availability under discharge fluctuations, as both fish and macrophytes are prone to dessication and require aquatic habitat persistence during the dry-season. Invertebrates, due to several well-known strategies to resist to water level fluctuations (Stanley et al., 1994; Vieira et al., 2004), are less dependent on water availability. This idea can be supported by the observed importance of the catchment area (clearly related to water availability) in the correlations between WFD data and all biological elements. Catchment area was also important to the correlation with fishes in Mountain Rivers, were the water availability is a key factor in supporting fish communities.

Lowland rivers showed a high number of significant correlations between aquatic communities and environmental parameters categories, which may also be related to more stable conditions and to the greater water availability in Lowland rivers, 
Table 5. Percentage of significance obtained by mantel correlations between environmental categories and each biological element, for Lowland rivers $\left({ }^{*} p<0.05\right.$; $\left.* * p<0.01\right)$. Down mantel correlations whose $p<0.1$ are mentioned the most important single parameters that account for the global correlation

\begin{tabular}{|c|c|c|c|}
\hline & \multicolumn{3}{|l|}{ Aquatic communities } \\
\hline & Macrophytes & Invertebrates & Fishes \\
\hline \multicolumn{4}{|l|}{ Rivers S05, S06 } \\
\hline \multirow[t]{6}{*}{ Habitat } & $6.9 \%$ & $0.1 \%(* *)$ & $56.0 \%$ \\
\hline & & Mesolithal (0.533) & \\
\hline & & Akal (0.417) & \\
\hline & & Microlithal (0.391) & \\
\hline & & Macrolithal (0.357) & \\
\hline & & Psammal (0.259) & \\
\hline \multirow[t]{5}{*}{ Global features } & $29.3 \%$ & $92.0 \%$ & $3.6 \%(*)$ \\
\hline & & & Shading $(0.306)$ \\
\hline & & & Mean slope val. (0.273) \\
\hline & & & Length rip. vegt. (0.236) \\
\hline & & & Width rip. vegt. (0.199) \\
\hline \multirow[t]{3}{*}{ WFD } & $0.6 \%(* *)$ & $12.8 \%$ & $3.5 \%(*)$ \\
\hline & Catch. area (0.298) & & Catch. area (0.268) \\
\hline & Altitude (0.118) & & Altitude $(0.121)$ \\
\hline \multicolumn{4}{|l|}{ Rivers K02, U23 } \\
\hline \multirow[t]{4}{*}{ Habitat } & $0.1 \%(* *)$ & $0.2 \%(* *)$ & $0.7 \%(* *)$ \\
\hline & Psammal (0.593) & Microlithal (0.338) & Microlithal (0.409) \\
\hline & Microlithal (0.304) & Psammal (0.294) & Xylal (0.243) \\
\hline & & Xylal (0.104) & Mesolithal (0.224) \\
\hline \multirow[t]{4}{*}{ Global features } & $0.7 \%(* *)$ & $0.1 \%(* *)$ & $0.1 \%(* *)$ \\
\hline & Shading $(0.425)$ & Shading $(0.518)$ & Riffles/pools rel. (0.560) \\
\hline & Mean slope val. (0.354) & Max. depth (0.373) & Width rip. vegt. $(0.465)$ \\
\hline & & Riffles/pools rel. (0.359) & Max. depth (0.387) \\
\hline \multirow[t]{2}{*}{ WFD } & $25.6 \%$ & $1.0 \%(*)$ & $4.6 \%(*)$ \\
\hline & & Longitude $(0.555)$ & Longitude (0.412) \\
\hline
\end{tabular}

than in Mountain rivers (Reyjol et al., 2003). Under these conditions, more stable communities can establish themselves in aquatic ecosystems and maintain a greater dependency on environmental parameters. For Mediterranean rivers, apart from WFD parameters, only fishes had a significant correlation with habitat parameters. This may be due to the lower stability of Mediterranean aquatic communities. Fish habitat relationships in Mediterranean rivers, particularly in intermittent ones, are highly dynamics due to seasonal habitats patchiness. Thus although fish can present a quite plastic habitat use along the year, in certain periods there are a strong habitat selectivity, namely for reproduction in spring and for individual survival during the dry-season (Ilhéu, 2004).
In Mountain rivers, all biological elements were correlated with the global features data, contrasting with Lowland rivers were only a significant correlation was detected for macrophytes. This fact confirms the assumptions of the river continuum concept (Vannote et al., 1980), predicting higher dependency of headwaters (Mountain rivers) from the allochtoneous inputs, as supported by the importance assumed by the shoreline covered with woody riparian vegetation (length rip.).

At the same major spatial scale the importance of latitude and longitude on the correlations observed between WFD data and biological elements was evident. This fact can result from climatic aspects dependent on the geographical localization or on the biogeographic distribution 
Table 6. Percentage of significance obtained by mantel correlations between environmental categories and each biological element, for Mediterranean rivers $\left({ }^{*} p<0.05 ;{ }^{*} p<0.01\right)$. Down mantel correlations whose $p<0.1$ are mentioned the most important single parameters that account for the global correlation

\begin{tabular}{llll}
\hline & Aquatic communities & & \\
\cline { 2 - 3 } & Macrophytes & Invertebrates & Fishes \\
\hline $\begin{array}{l}\text { Rivers H04, I06 } \\
\text { Habitat }\end{array}$ & $50.9 \%$ & $1.4 \%\left(^{*}\right)$ & $1.7 \%(*)$ \\
& & Akal $(0.393)$ & Mesolithal $(0.520)$ \\
& & Microlithal $(0.383)$ & Microlithal $(0.502)$ \\
& & Psammal $(0.345)$ & Akal $(0.453)$ \\
Global features & & Mesolithal $(0.271)$ & CPOM $(0.391)$ \\
WFD & & Ter. plants $(0.217)$ & - \\
& $0.2 \%(* *)$ & - & $0.9 \%(* *)$ \\
& Altitude $(0.528)$ & $0.2 \%(* *)$ & Catch. area $(0.649)$ \\
Catch. area $(0.496)$ & Catch. area $(0.777)$ & Latitude $(0.533)$ \\
& & Altitude $(0.624)$ & Longitude $(0.518)$ \\
\hline
\end{tabular}

Rivers H04, 105

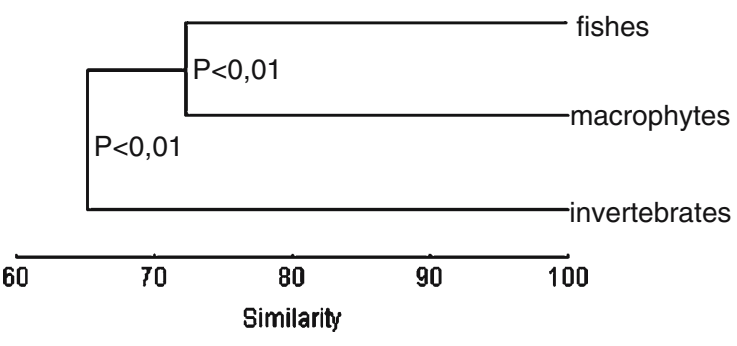

Figure 8. Cluster analyses of all biological elements for the subgroup of Mediterranean, rivers. Critical level of significance ( $p$ ) mentioned for all the partial aglomerations.

of taxa across Europe. Due to the general similarities of climatic aspects of the regions covered by each river type, the second hypothesis seems to be a better explanation.

Separate ordinations for each aquatic community within each core river type denoted a high dependence on the geographical location. However, a more detailed analysis of subgroups of major river types (i.e., regional and local scale) showed similar results. The only exception was the two subgroups of Mountain Rivers, where no significant correlations were obtained among the aquatic communities. In contrast to Lowland rivers, only two significant correlations were obtained between environmental parameters categories and aquatic communities. Greater hydraulic disturbance, leading to less stable communities (Townsend et al., 1983; Reichard et al., 2002; Johnson et al., 2003; Smith et al., 2003) can decrease the strength of linkages between aquatic communities and environmental parameters. These results emphasize the importance of physical factors on aquatic ecosystems, causing different linkages between aquatic communities and different dependencies on environmental parameters (Townsend et al., 1983; Townsend, 1989; Voelz \& McArthur, 2000; Wright \& Li, 2002). Concerning Mountain Rivers, the low-richness observed of macrophytes and fishes can also contribute to the weakness of the links among the biological elements, as well as to the absence of significant correlations between all environmental data categories and those two biological elements.

Biological elements of the two subgroups of Lowland rivers (S05/S06 and K02/U23) showed similar clusters, but with completely different correlations with environmental category data. This fact suggests that links among biological elements are more dependent on relationships established among aquatic communities than on the influence of environmental parameters.

Concerning Mediterranean rivers, at a lower spatial scale, catchment area continued to be an important parameter controlling the establishment of aquatic communities, thus suggesting the 
importance of water availability at different scales for Mediterranean rivers.

Generally, when mantel correlations were carried out at the larger regional level, WFD parameters were significantly correlated with almost all aquatic communities. However, when this analysis was carried out at a smaller spatial scale (regional or local), the number of significant correlations to WFD parameters diminished, while significant correlations to habitats and global features increased. This tendency partially agrees with the hierarchical theory of river formation (Jensen et al., 1996; Verdonschot, 2000; Crook et al., 2001; Li et al., 2001; Weigel et al., 2003) because there are no environmental parameters specific to any spatial scale.

The present study confirmed that links among biological elements are different for different core river types, and are influenced by water availability. These links tend to be consistent for different spatial scales, except if they are weak. The influence of environmental parameters is dependent on the spatial scale. Reach and mesohabitat environmental parameters tend to explain aquatic communities at a lower spatial scale, while geographical parameters tend to explain the communities at a major spatial scale.

\section{Acknowledgements}

This study was funded by the EU research project STAR from the European Commission, 5th Framework Program, Energy, Environment and Sustainable Development, Key Action Water, Contract No. EVK1-CT2001-00089. We would like to thank to STAR partners for the data availability and to two unknown reviewers for their comments that largely contributed to the scientific improvement of this paper.

\section{References}

Allouche, S., 2002. Nature and function of cover for riverine fish. Bulletin Francais de La Peche et la Pisciculture 356(66): 297-324.

AQEM consortium, 2002. Manual for the application of the AQEM system. A comprehensive method to assess European streams using benthic macroinvertebrates, developed for the purpose of the Water Framework Directive. Version 1.0 February 2002.

Armitage, P. D., 1995. Faunal Community change in response to flow manipulation. In Harper, D. M. \& J. D. Ferguson, (eds), The Ecological Basis of River Management. John Wiley \& Sons, New York, 59-78.

Armitage, P. D. \& C. E. Cannan, 2000. Annual changes in summer patterns of mesohabitat distribution and associated macroinvertebrate assemblages. Hydrological Processes 14: 3161-3179.

Armitage, P. D. \& R. J. M. Gunn, 1996. Differential response of benthos to natural and anthropogenic disturbances in 3 lowland streams. Internationale Revue der Gesamten Hydrobiologia 81: 161-181.

Balci, P. \& J. H. Kennedy, 2003. Comparison of chironomids and other macroinvertebrates associated with Myriophyllum spicatum and Heteranthera dubia. Journal of Freshwater Ecology 18: 235-247.

Beisel, J. N., P. Usseglio-Polaterra, S. Thomas \& J. C. Moretou, 1998. Stream community structure in relation to spatial variation: the influence of mesohabitat characteristics. Hydrobiologia 389: 73-88.

Bernardo, J. M., M. Ilhéu, P. Matono \& A.M. Costa, 2003. Interannual variation of fish assemblage structure in a Mediterranean river: implications of streamflow on the dominance of native or exotic species. River Research and Application 19: 1-12.

Bio, A. M. F., P. De Becker, E. De Bie, W. Huybrechts \& M. Wassen, 2002. Prediction of plant species distribution in lowland river valleys in Belgium: modelling species response to site conditions. Biodiversity and Conservation 11: 21892216

Clark, K. R. \& R. M. Warwick, 1980. Changes in Marine Communities: An Approach to Statistical Analysis and Interpretation. Natural Environmental Council, UK.

Casas, J. J., 1997. Invertebrate assemblages associated with plant debris in a backwater of a mountain stream: natural leaf packs vs. debris dam. Journal of Freshwater Ecology 12: 39-49.

Cheruvelil, K. S., P. A. Soranno \& R. D. Serbin, 2000. Macroinvertebrates associated with submerged macrophytes: sample size and power to detect effects. Hydrobiologia 441: 133-139.

Crook, D. A., A. I. Robertson, A. J. King \& P. Humphries, 2001. The influence of spatial scale and habitat arrangement on diel patterns of habitat use by two lowland river fishes. Oecologia 129: 525-533.

Dahl, J. \& L. A. Greenberg, 1998. Effects of fish predation and habitat type on stream benthic communities. Hydrobiologia 361: 67-76.

Furse, M., D. Hering, O. Moog, P. Verdonschot, R. K. Johnson, K. Brabec, K. Gritzalis, A. Buffagni, P. Pinto, N. Friberg, J. Murray-Bligh, J. Kokes, R. Alber, P. UsseglioPolatera, P. Haase, R. Sweeting, B. Bis, K. Szoszkiewicz, H. Soszka, G. Springe, F. Sporka, I. Krno, 2006. The STAR project: context, objectives and approaches. Hydrobiologia 566: 3-29.

Ilhéu, M., 2004. Patterns of habitat use by freshwater fishes in Mediterranean rivers. PhD Thesis, University of Évora, Évora. 
Jensen, M. E., P. Bourgeron, R. Everett \& I. Goodman, 1996. Ecosystem management: a landscape ecology perspective. Water Research 32: 203-216.

Johnson, L. B., D. H. Breneman \& C. Richards, 2003. Macroinvertebrate community structure and function associated with large wood in low gradient streams. River Research and Applications 19: 199-218.

Li, J. L., A. Herlihy, W. Gerth, P. Kaufmann, S. Gregory, S. Urquhart \& D. P. Larsen, 2001. Variability in stream macroinvertebrates at multiple spatial scales. Freshwater Biology 46: 1-87.

Petts, G. E., 2000. A perspective on the abiotic process sustaining the ecological integrity of running waters. Hydrobiologia 422/423: 15-27.

Reichard, M., P. Jurajda \& M. Ondrackova, 2002. Interannual variability in seasonal dynamics and species composition of drifting young-of-the-year fishes in two European lowland rivers. Journal of Fish Biology 60: 87-101.

Reyjol, Y., A. Compin, A. Ibarra \& P. Lim, 2003. Longitudinal diversity patterns in streams: comparing invertebrates and fish communities. Archiv fur Hydrobiologie 157: 525-533.

Rosenfeld, J. S., 1997. The effect of large macroinvertebrate herbivores on sessile epibenthos in a mountain stream. Hydrobiologia 344: 75-79.

Smith, H., P. J. Wood \& J. Gunn, 2003. The influence of habitat structure and flow permanence on invertebrate communities in karst spring systems. Hydrobiologia 510: 53-66.

Stanley, E. H., D. L. Buschman, A. J. Boulton, N. B. Grimm \& S. G. Fisher, 1994. Invertebrate resistance and resilience to intermittency in a desert stream. American Midland Naturalist 131: 288-300.

Strayer, D. L., C. Lutz, H. M. Malcom, K. Munger \& W. H. Shaw, 2003. Invertebrate communities associated with a native (Vallisneria americana) and an alien (Trapa natans) macrophyte in a large river. Freshwater Biology 48: 19381949.

Shoup, D.E., R. E. Carlson \& R. T. Heath, 2003. Effects of predation risk and foraging return on the diel use of vegetated habitat by two size-classes of bluegills. Transactions of the American Fisheries Society 132: 590-597.

ter Braak, C. J. F. \& P. Smilauer, 1998. 'CANOCO Reference Manual and User's Guide to Canoco for Windows'. Microcomputer Power, Ithaca, New York, 351 pp.

Tolonen, K. T., H. Hamalainen, I. J. Holopainen, K. Mikkonen \& J. Karjalainen, 2003. Body size and substrate association of littoral insects in relation to vegetation structure. Hydrobiologia 499: 179-190.

Townsend, C. R., 1989. The patch dynamic concept of stream community ecology. Journal of North American Benthological Society $8: 36-50$.

Townsend, C. R., A. G. Hidrew \& J. Francis, 1983. Community structure in some southern English streams: the influence of physicochemical factors. Freshwater Biology 13: 521-544.

Vannote, R. L., G. W. Minshall, K. W. Cummins, J. R. Sedell \& E. Cushing, 1980. The river continuum concept. Canadian Journal of Fisheries and Aquatic Sciences 37: 130-137.
Verdonschot, P. F., 2000. Integrated ecological assessment methods as a basis for sustainable catchment management. Hydrobiologia 422/423: 389-412.

Verdonschot, P. F. M., 2006. Evaluation of the use of Water Framework Directive typology descriptors, reference sites and spatial scale in macroinvertebrate stream typology. Hydrobiologia 566: 39-58.

Verdonschot, P. F. \& R. C. Nijboer, 2004. Testing the European stream typology of the water framework directive for macroinvertebrates. Hydrobiologia 516: 35-54.

Vieira, N. K. M., W. H. Clements, L. S. Guevara \& B. F. Jacobs, 2004. Resistance and resilience of stream insect communities to repeated hydrologic disturbances after a wildfire. Freshwater Biology 49: 1243-1259.

Voelz, N. J. \& J. V. McArthur, 2000. An exploration of factors influencing lotic insect species richness. Biodiversity and Conservation 9: 1543-1570.

Wagner, F. H. \& G. Bretschko, 2003. Riparian trees and flow paths between the hyporheic zone and groundwater in the Oberer Seebach, Austria. International Review of Hydrobiology 88: 129-138.

Ward, J. V., 1989. The four dimensional nature of lotic ecosystems. Journal of North American Benthological Society 8: 2-8.

Ward, J. V. \& K. Tockner, 2001. Biodiversity: towards a unifying theme for river ecology. Freshwater Biology 46: 807-819.

Warfe, D. M. \& L. A. Barmuta, 2004. Habitat structural complexity mediates the foraging success of multiple predator species. Oecologia 141: 171-178.

Weigel, B. M., L. Z. Wang, P. W. Rasmussen, J. T. Butcher, P. M. Stewart, T. P. Simon \& M. J. Wiley, 2003. Relative influence of variables at multiple spatial scales on stream macroinvertebrates in the Northern Lakes and Forest ecoregion, USA. Freshwater Biology 48: 1440-1461.

Willis, S. C., K. O. Winemiller \& H. Lopez-Fernandez, 2005. Habitat structural complexity and morphological diversity of fish assemblages in a Neotropical floodplain river. Oecologia 142: 284-295.

Wright, J. F., R. J. M. Gunn, J. M. Winder, R. Wiggers, K. Vowles, R. T. Clarke \& I. Harris, 2002. A comparison of the macrophyte cover and macroinvertebrate fauna at three sites on the River Kennet in the mid 1970s and late 1990s. Science of the Total Environment 282: 121-142.

Wright, K. K. \& J. L. Li, 2002. From continua to patches: examining stream community structure over large environmental gradients. Canadian Journal of Fisheries and Aquatic Sciences 59: 1404-1417.

Zimmer, K. K. D., M. A. Hanson \& M. G. Butler, 2003. Relationships among nutrients, phytoplankton, macrophytes, and fish in prairie wetlands. Canadian Journal of Fisheries and Aquatic Sciences 60: 721-730.

Zrum, L. \& B. J. Hann, 2002. Invertebrates associated with submersed macrophytes in a prairie wetland: effects of organophosphorus insecticide and inorganic nutrients. Archiv fur Hydrobiologie 154: 413-445. 